\title{
O Direito do Consumidor no Brasil e a Concretização dos Direitos Humanos
}

\author{
Juliano Scarpetta \\ Graduado em Direito pela Associação Catarinense de \\ Ensino; especialista em Direito Civil e Processo Civil pela \\ Associação Catarinense de Ensino; especialista em Direito \\ Empresarial pela Católica de Santa Catarina; mestrando \\ em Direito Econômico e Socioambiental pela Pontifícia \\ Universidade Católica do Paraná - PUCPR. juliano@ \\ bh.adv.br.
}

\section{Antônio Carlos Efing}

Mestre e doutor pela PUC-SP; professor titular da PUC-PR onde leciona na Graduação, especializações, Mestrado e Doutorado; professor da Escola da Magistratura do Paraná; membro do Instituto dos Advogados do Paraná; Advogado militante em Curitiba. ace@eradv.com.br.

\section{Resumo}

Em razão da nova forma de produção e organização social, predominantemente urbana, o consumo de produtos e serviços torna-se condição basilar à subsistência da população. A partir da promulgação da Constituição Federal de 1988 e da vigência do Código de Defesa do Consumidor (CDC) em 1990, criou-se um cenário benéfico aos consumidores para equilíbrio da relação perante os fornecedores, potencializando-se a visão social e humanista pretendida pelo legislador às relações de consumo. Determinadas proteções amparadas pelo CDC ligadas à saúde, segurança, alimentação e medicamentos acabam por concretizar e efetivar também direitos humanos pretendidos pelo legislador constituinte, prezando-se pela dignidade e permitindo condições plenas de desenvolvimento humano, em razão da necessidade indissociável de se consumir no atual cenário.

Palavras-chave: Consumidor. Tutela constitucional. Direitos humanos. Desenvolvimento humano. 
THE CONSUMER RIGHTS IN BRAZIL AND THE HUMAN RIGHTS CONCRETION

\begin{abstract}
Due to the new way of production and social organization, predominantly urban, consumption of products and services becomes the fundamental condition to population sustain. From the promulgation of the 1988 Constitution, and the start of the Consumer Protection Code (CDC) in 1990, it was created a beneficial scenario to consumers emerged to balance the relationship to suppliers, increasing a social and humanist vision intended by the legislator to consumer relations. Certain protections supported by the CDC related to health, safety, food and medicine, concrect and effective human rights intended by the constitutional legislator, valuing dignity and allowing full conditions of human development, due to of the inseparable need to consume in the current context.
\end{abstract}

Keywords: Consumer. Constitutional Guardianship. Human Rights. Human Development.

\title{
Sumário
}

1. Introdução. 2. 0 direito do consumidor no Brasil e sua evolução. 2.1. A tutela constitucional do consumidor. 2.2. A visão social e humanista no Código de Defesa do Consumidor. 3. Os direitos humanos e a realidade brasileira. 4 . Os direitos do consumidor e a efetivação dos direitos humanos. 5. Conclusão. 6. Referências. 


\section{INTRODUÇÃO}

Em decorrência das transformações econômicas e sociais ocorridas desde o século passado, não há como desvincular o atual modelo de sociedade das relações de consumo. A subsistência da população e a manutenção das economias mundiais dependem, pelo menos num futuro próximo, da conservação deste modelo de produção em larga escala e padronização de produtos e serviços.

O ser humano mostra-se cada vez mais afastado da essência de sua origem e relação com os elementos naturais que o cercam. Ainda que grande parte da sociedade não entenda tal condição de modo pejorativo, esta realidade potencializa duas das principais características intrínsecas às relações de consumo: a vulnerabilidade e a hipossuficiência ${ }^{1}$ em relação aos fornecedores. ${ }^{2} \mathrm{O}$ poder das grandes corporações no cenário mundial cria ao consumidor, ${ }^{3}$ em certos casos, uma relação obrigatória de submissão aos produtos destes grupos empresariais.

Tamanha é a dependência do consumidor que, em determinados casos, o controle e risco sobre sua saúde, segurança e até mesmo a vida são obrigatoriamente confiados a fornecedores, gerando situação de

\footnotetext{
1 "Quanto à hipossuficiência, trata-se de impotência do consumidor, seja de origem econômica seja de origem de outra natureza, para apurar e demonstrar a causa do dano cuja responsabilidade é imputada ao fornecedor. Pressupõe uma situação em que concretamente se estabeleça uma dificuldade muito grande para o consumidor desincumbir-se de seu natural o nus probandi, estando o fornecedor em melhores condições para dilucidar o evento danoso" (Theodoro Junior, 2004, p. 143).

${ }^{2}$ Código de Defesa do Consumidor em seu artigo $3^{\circ}$ assevera que fornecedor é toda pessoa física ou jurídica, pública ou privada, nacional ou estrangeira, bem como os entes despersonalizados, que desenvolvem atividade de produção, montagem, criação, construção, transformação, importação, exportação, distribuição ou comercialização de produtos ou prestação de serviços.

${ }^{3}$ De acordo com o Código de Defesa do Consumidor, em seu artigo $2^{\circ}$, consumidor é toda pessoa física ou jurídica que adquire ou utiliza produto ou serviço como destinatário final. Parágrafo único. Equipara-se ao consumidor a coletividade de pessoas, ainda que indetermináveis, que haja intervindo nas relações de consumo.
} 
subordinação e dependência perante estes. O descumprimento dos princípios de defesa do consumidor pode gerar condição de penúria ou danos irreversíveis em afronta aos direitos humanos fundamentais do indivíduo e de sua coletividade.

O escopo do presente estudo é justamente abordar a importância dos direitos do consumidor como forma de concretização e efetivação de direitos humanos, em razão da limitação de autonomia social do cidadão consumidor perante o atual cenário socioeconômico. Há que se valer do direito do consumidor por seus princípios mais basilares em relação ao estabelecimento de condições mínimas de sobrevivência com os adequados serviços de saúde, fornecimento de energia elétrica, água e saneamento, produção e distribuição de medicamentos e alimentos, como forma de garantir dignidade mínima aos que dependem desses produtos e serviços.

A defesa dos consumidores com relação a possíveis defeitos ou danos gerados por serviços ou produtos supérfluos, que geram exclusivamente conforto e praticidade, como TV a cabo, academia, entre outros, não é o foco da presente abordagem. Com efeito, o que se pretende é a sustentação por meio do direito consumerista, e nos limites de sua batuta, de condições dignas de vida e mantença, tal qual protegido pela maioria dos direitos sociais, dentre eles os direitos humanos.

A tese do diálogo das fontes propõe uma nova forma de interpretação e aplicação conjunta das fontes do Direito, valendo-se de mais de uma base legal em busca não só da solução de conflitos ou colisões legais, mas também da plena defesa dos interesses do sujeito e da coletividade. Para Cláudia Lima Marques, a nova hierarquia é a coerência dada pelos valores constitucionais e a prevalência dos direitos humanos (Marques, 2012).

Ainda que o Brasil esteja aquém de outras nações com relação à efetivação dos direitos humanos, significativos avanços ocorreram com relação aos direitos de primeira dimensão, solidificando-se as liberdades 
civis e políticas nas últimas décadas. Os direitos humanos de segunda e terceira dimensões passam a ser almejados, potencializando-se os direitos sociais, econômicos, culturais, não somente individuais, mas também coletivos, a exemplo do direito dos consumidores.

Seguindo os ensinamentos de Flávia Piovesan, no momento em que os seres humanos se tornam supérfluos e descartáveis, no momento em que vige a lógica da destruição, em que é abolido o valor da pessoa humana, torna-se necessária a reconstrução dos direitos humanos (Piovesan, 2014a). É de lamentar que muitos consumidores dependentes de serviços básicos (locomoção, aluguel, telefone, alimentação, luz, etc.) sejam vistos por seus fornecedores como objetos descartáveis. Em razão da dependência de certos produtos e serviços, a desídia de fornecedores acaba por ferir não somente direitos dos consumidores, mas também direitos humanos de segunda e terceira dimensões. Neste sentido, pretende-se abordar algumas circunstâncias em que a aplicabilidade dos direitos dos consumidores, juntamente com o aparato estatal, também garantem a efetivação dos direitos humanos.

\section{O DIREITO DO CONSUMIDOR NO BRASIL E SUA EVOLUÇÃO}

\subsection{A Tutela Constitucional do Consumidor}

Em razão da nova forma de produção e organização social, predominantemente urbana, emerge no período da Revolução Industrial na Europa uma nova forma de se consumir. Surgem então os primeiros passos para proteção dos consumidores, em razão da condição de desigualdade que se iniciara perante os fornecedores. 
Posteriormente, com destaque ao período pós-Segunda Guerra Mundial, passa a imperar a denominada "cultura de massa”, denominação dada ao comportamento adotado pelos consumidores com o surgimento dos meios de comunicação de massa. A divulgação de ideias, conceitos e produtos induz a sociedade ao consumo, o qual se dá predominantemente em mercadorias padronizadas e industrializadas. $\mathrm{O}$ trabalhador passa também a ser um consumidor formador do elo de produção. Deve-se consumir para alimentar o sistema, e o trabalhador-consumidor inspira suas conquistas pessoais e as materializa usualmente com o consumo. Conforme Nunes (2012, p. 43):

Com o crescimento populacional nas metrópoles, que gerava aumento de demanda e, portanto, uma possibilidade de aumento da oferta, a indústria em geral passou a querer produzir mais, para vender para mais pessoas (o que era e é legítimo). Passou-se então a pensar num modelo capaz de entregar, para um maior número de pessoas, mais produtos e mais serviços. Para isso, criou-se a chamada produção em série, a "standartização" da produção, a homogeneização da produção.

Se antes o trabalho era voltado à produção agrícola e artesanal, a partir desta nova formatação social o foco do trabalho é o dinheiro, que por sua vez permite a subsistência por meio do consumo.

No Brasil, em meados da década de 50 do século 20, o Direito do Consumidor passa a tomar corpo. Foram debatidas e sancionadas leis e decretos sobre saúde, proteção econômica e comunicações em benefício da coletividade. Na década de 80 os debates e estudos na elaboração da Constituição tinham alicerce num novo cenário, em compasso com a evolução social tão almejada no país. A diminuição das desigualdades sociais era a meta nesta nova fase, objetivando a igualdade material também nas relações de consumo. A vulnerabilidade e a insegurança decorrentes principalmente do período de liberalismo econômico não poderiam ser 
deslembradas pelo Estado, cabendo sua intervenção de forma preventiva e repressiva aos excessos e descumprimentos legais tentados pelos fornecedores.

Tamanha importância foi dada, que nos anais da Assembleia Nacional Constituinte que culminou na Carta Magna de 1988 estão registrados amplos debates acerca do tema, visando à máxima proteção do consumidor pelo legislador. Conferiu-se status de garantia fundamental inserida no artigo $5^{\circ}$, inciso XXXII, iniciando nova e salutar etapa no contexto jurídico e social da nação.

$\mathrm{Na}$ qualidade de direito fundamental mantém ele predomínio em relação aos demais. Não obstante, lhe é conferida estabilidade constitucional conforme disposto no artigo $60, \$^{\circ}{ }^{\circ}$, inciso IV da Constituição Federal. A defesa do consumidor é cláusula pétrea, portanto vedada sua alteração ou exclusão da Carta Magna. O legislador constitucional também conferiu à defesa do consumidor condição de princípio geral da atividade econômica nacional, disposto no artigo 170, inciso V, asseverando-a no rol de sustentação ao modelo econômico e político. Equipara-se esta garantia a outros importantes princípios, tais como da soberania nacional, propriedade privada e sua função social, livre concorrência, entre outros.

José Afonso da Silva (2006, p. 262) assevera a importância do supracitado dispositivo constitucional:

Realça de importância, contudo, sua inserção entre os direitos fundamentais, com o que se erigem os consumidores à categoria de titulares de direitos constitucionais fundamentais. Conjugue-se a isso com a consideração do art. 170, V, que eleva a defesa do consumidor à condição de princípio da ordem econômica. Tudo somado, tem-se o relevante efeito de legitimar todas as medidas de intervenção estatal necessárias a assegurar a proteção prevista. 
Ademais, o Ato das Disposições Constitucionais Transitórias (ADCT) dispõe em seu artigo 48 que caberá ao Congresso, no prazo de 120 dias, a elaboração de um Código de Defesa do Consumidor. Embora não se tenha atendido ao prazo disposto no $\mathrm{ADCT}$, o Código de Defesa do Consumidor foi criado em 11 de setembro de 1990, com a publicação da lei 8.078, passando a vigorar esta importante codificação, a qual aborda e delimita diferentes aspectos desta relação.

Para Ada Pellegrini Grinover (2004, p. 6) "a proteção do consumidor é um desafio da nossa era e representa, em todo mundo, um dos temas mais atuais do Direito”, ensinando que:

Não é difícil explicar tão grande dimensão para um fenômeno jurídico totalmente desconhecido no século passado e em boa parte deste. $\mathrm{O}$ homem do século XX vive em função de um novo modelo de associativismo: a sociedade de consumo, caracterizada por um número crescente de produtos e serviços, pelo domínio do crédito e do marketing, assim como pelas dificuldades de acesso à justiça.

Desse modo, ainda que o sistema de proteção do consumidor seja de recente criação, sua eficácia galga degraus cada vez mais altos. Sua sólida base constitucional, somada aos elementos materiais inseridos no Código criam benéficos efeitos que são difundidos socialmente. Não raro pessoas de simples trato têm conhecimento de seus direitos como consumidores e dever de cumprimento pelos fornecedores. Com efeito, a eficácia do sistema de defesa do consumidor permite sua efetividade, que deve ser entendida também em prol da proteção dos direitos humanos dada sua importância social na atualidade.

\subsection{A Visão Social e Humanista no Código de Defesa do Consumidor}

Desde 11 de março de 1991, quando entrou em vigor no Brasil, o Código de Defesa do Consumidor (CDC) cumpre exemplarmente seu papel de garantidor de direitos e atribuidor de deveres inerentes às rela- 
ções de consumo. Seu microssistema, ainda que recente, é peça de destaque dentro do extenso, e muitas vezes inerte, macrossistema jurídico brasileiro.

É de se destacar que o trabalho de elaboração do Código de Defesa do Consumidor pelo legislador ordinário surge de um anteprojeto desenvolvido por juristas do mais alto escalão. Entre os anos de 1988 e 1989, logo após a promulgação da Constituição Federal, o Congresso Nacional contou com a colaboração destes juristas, além de membros de associações de classes, para a criação de um esboço, o qual nortearia o trabalho legislativo. Tal anteprojeto, salvo partes vetadas, tornou-se base do regramento para as relações de consumo.

O CDC avoca não somente elementos materiais acerca de reparos, substituições e descumprimentos contratuais relativos a produtos e serviços. Vai além quando assegura proteção especial às crianças, idosos, natureza, e proteção à vida e segurança. Garante a reparação de danos materiais e morais, ao mesmo tempo protege individualmente o consumidores, gerando efeitos difusos à coletividade destes. A este respeito Antônio Carlos Efing (2011, p. 25) assevera:

A responsabilidade dos produtores frente à massa dos consumidores torna-se coletiva, cabendo aos primeiros a seguridade de sua produção face aos usuários. Em homenagem ao bem-estar da sociedade e das relações humanas, o legislador consagra a proteção do consumidor, já que se preocupa com os acidentes advindos do uso de produtos e com problemas decorrentes da prestação de serviços.

Os direitos básicos do consumidor elencados no CDC indicam a preocupação social almejada pelo legislador, que com amparo constitucional pôde criar legislação de ampla tutela e eficácia. Cláudia Lima Marques (1992, p. 12) observou esta vocação do Código desde sua entrada em vigor em 1991: 
De uma visão liberal e individualista do Direito Civil, passamos a uma visão social, que valoriza a função do direito como ativo garante do equilíbrio, como protetor da confiança e das legítimas expectativas das relações de consumo no mercado.

Em harmonia com tais preceitos, seu artigo $6^{0}$ assevera que são direitos básicos do consumidor: "I - a proteção da vida, saúde e segurança contra os riscos provocados por práticas no fornecimento de produtos e serviços considerados perigosos ou nocivos” (Brasil, 2015).

Parte-se da premissa de que a hipossuficiência e a vulnerabilidade do consumidor são preceitos basilares à aplicação deste microssistema, e não se pode confundir e utilizar um conceito como se o outro o fosse. Nas lições de Flávio Tartuce e Daniel Neves (Tartuce; Neves, 2012), trata-se a hipossuficiência de um conceito fático e não jurídico, fundado em uma disparidade ou discrepância notada no caso concreto. Ela pode ser característica de alguns consumidores, e não de todos. Segundo James Marins (2000, p. 33), é necessária a comprovação da "precariedade de condições culturais e materiais do consumidor” para a efetiva formação da relação. A hipossuficiência limita o consumidor, prejudicando a melhor comprovação dos eventuais vícios e irregularidades aos bens ou serviços adquiridos.

Por sua vez a vulnerabilidade é inerente à própria condição de consumidor, todos que se encaixam nesta categoria são vulneráveis. Apresenta-se disposta no inciso I do artigo $4^{\circ}$, o qual estabelece o reconhecimento da vulnerabilidade do consumidor no mercado de consumo. Esta premissa de vulnerabilidade dos consumidores pode ser potencializada, atribuindo-se aspectos ainda mais sociais e humanistas a certos grupos de consumidores, os quais assumem a condição de hipervulneráveis. Aqueles que, em vista de sua particular condição, tais como idosos, crianças, deficientes mentais, analfabetos, mostram-se ainda mais expostos à periculo- 
sidade e nocividade de determinados produtos, dependência de serviços e às práticas comerciais desempenhadas pelos fornecedores, merecendo proteção especial de modo a se manter o equilíbrio pretendido do CDC.

A proteção destes consumidores hipervulneráveis ${ }^{4}$ é ainda mais ativa e o Código destina especial atenção a eles. O CDC assevera em seu artigo 39, inciso IV, algumas práticas ilícitas, também denominadas como abusivas, ao fornecedor que "prevalecer-se da fraqueza ou ignorância do consumidor, tendo em vista sua idade, saúde, conhecimento ou condição social, para impingir-lhe seus produtos ou serviços”. Ao seu encontro, e ratificando tamanha importância que foi dada pelo legislador, o artigo 76, inciso IV, alínea b do CDC prevê sanções penais aos fornecedores que se prevalecerem "em detrimento de operário ou rurícola; de menor de 18 ou maior de 60 anos ou de pessoas portadoras de deficiência mental interditadas ou não".

Há também a regulação das práticas publicitárias descritas no artigo 37 do CDC, em especial aquelas consideradas abusivas, conforme seu parágrafo $2^{\underline{0}}{ }^{5} \mathrm{O}$ caráter da abusividade não tem, necessariamente,

${ }^{4}$ Segundo o ministro do STJ Antônio Herman de Vasconcellos e Benjamin, no recurso especial 586.316/MG: “O Código de Defesa do Consumidor, é desnecessário explicar, protege todos os consumidores, mas não é insensível à realidade da vida e do mercado, vale dizer, não desconhece que há consumidores e consumidores, que existem aqueles que, no vocabulário da disciplina, são denominados hipervulneráveis, como as crianças, os idosos, os portadores de deficiência, os analfabetos e, como não poderia deixar de ser, aqueles que, por razão genética ou não, apresentam enfermidades que possam ser manifestadas ou agravadas pelo consumo de produtos ou serviços livremente comercializados e inofensivos à maioria das pessoas.” (Brasil. Superior Tribunal de Justiça. Recurso Especial n. ${ }^{\circ}$ 586.316, da $2^{\mathrm{a}}$ Turma, Relator: Ministro Herman Benjamin 2007).

${ }^{5} \S 2^{\circ}$ É abusiva, dentre outras, a publicidade discriminatória de qualquer natureza, a que incite à violência, explore o medo ou a superstição, se aproveite da deficiência de julgamento e experiência da criança, desrespeita valores ambientais, ou que seja capaz de induzir o consumidor a se comportar de forma prejudicial ou perigosa à sua saúde ou segurança (Brasil. Lei n. 8.078, de 11 de setembro de 1990. Institui o Código de Defesa do Consumidor. Diário Oficial da União, Brasília, 12 set.1990). 
relação direta com o produto ou serviço oferecido, mas sim com os efeitos da propaganda que possam causar algum mal ou constrangimento ao consumidor (Nunes, 2000).

Mais uma vez a visão social é asseverada no Código, limitando os efeitos persuasivos da publicidade em razão da condição de certos grupos de consumidores, bem como prezando por outros tantos quesitos morais inseridos na norma. Ao encontro desta visão social do microssistema consumerista, quando se aplicam as proteções sociais lá preconizadas em relação a serviços de saúde, medicamentos, alimentos e demais fornecimentos básicos e indissociáveis ao modo de vida atual, certifica-se que o Código de Defesa do Consumidor é importante ferramenta de efetivação também de direitos humanos.

Os direitos de segunda e terceira dimensão podem ser alcançados por meio do CDC, valendo-se o operador de ferramentas de aplicação tais como o diálogo das fontes, a Teoria Estruturante do Direito defendida por Friedrich Müller ${ }^{6}$ e de outras tantas formas de interpretação e aplicação legal com objetivo de proteger o bem jurídico mais precioso, qual seja, a vida e sua dignidade.

\footnotetext{
${ }^{6}$ A teoria estruturante do Direito foi democraticamente desenvolvida a partir da metade dos anos 60 com base na prática cotidiana, abrangendo a dogmática jurídica (especialmente os direitos fundamentais e humanos), a metodologia jurídica, a teoria (da norma) jurídica e a teoria constitucional, englobando também a linguística jurídica. A teoria estruturante do Direito não é apenas uma nova concepção, é uma concepção inovadora do Direito. Resulta pela primeira vez, de um conceito pós-positivista de norma jurídica. A norma jurídica não se encontra já pronta nos textos legais; nestes encontram-se apenas formas primárias, os textos normativos. A norma só será produzida em cada processo particular de solução jurídica de um caso, em cada decisão judicial (Müller, Friedrich. Teoria e interpretação dos Direitos Humanos Nacionais e Internacionais - especialmente na ótica da teoria estruturante do Direito. In: Clève, C. M.; Pagliarini, A. C.; Sarlet, I. W. (Coord.). Direitos Humanos e Democracia. Rio de Janeiro, Forense, 2007. p. 45-52.
} 


\section{3-OS DIREITOS HUMANOS \\ E A REALIDADE BRASILEIRA}

Assim como se pode afirmar que não há Constituição sem direitos fundamentais, então também é verdadeira a assertiva de que não há Constituição sem democracia (Cleve; Pagliarini; Sarlet, 2007). Durante o período ditatorial no Brasil (de 1964 a 1985), ainda que a Constituição em vigor (1967) dispusesse de um rol de direitos fundamentais, a garantia de tais direitos era relativa em razão de a população não poder eleger seus governantes, que por sua vez mantiveram regime malquisto por todos, ferindo severamente os direitos humanos no período denominado "anos de chumbo".

Em 1985 inicia-se uma nova etapa com o fim do regime ditatorial e com a retomada formal do processo democrático-eleitoral e político no país. De igual forma, materializou-se o processo de elaboração e promulgação da Constituição Federal de 1988, a qual iniciou nova etapa na consagração dos direitos humanos.

Conforme ensina Flávia Piovesan (2014b, p. 546), "introduz o texto constitucional avanço extraordinário na consolidação dos direitos e garantias fundamentais, situando-se como documento mais abrangente e pormenorizado sobre os direitos humanos jamais adotado no Brasil”.

A partir de sua promulgação de 1988, a Constituição alavanca a ânsia social em se estabelecer um novo norte, sem esquecer o infeliz e recente passado, mas criando mecanismos para que as barbáries de parte a parte cometidas nos "anos de chumbo" não voltassem a intimidar e lanhar a população. Em complemento, Flávia Piovesan (2014b, p. 61) explicita:

O valor da dignidade humana impõe-se como núcleo básico e informador do ordenamento jurídico brasileiro, como critério e parâmetro de valoração a orientar a interpretação e compreensão do sistema constitucional instaurado em 1988. 
A bandeira dos direitos humanos solidifica-se no Brasil não só por sua forma legal, mas também pela reivindicação dos movimentos sociais. Em verdade, um sustenta o outro e todos asseguram a aplicabilidade das garantias conquistadas e daquelas que ainda se buscam. Comissões de direitos humanos são constituídas ou fortalecidas nas Casas Legislativas dos Estados e de alguns municípios. O poder Executivo propõe programas de direitos humanos. A sociedade civil também se mobiliza na criação de organizações acerca do tema.

Seguindo-se do tema central deste artigo, há que se destacar que diversas comissões de direitos humanos existentes nos Estados e municípios têm como pauta também a defesa do consumidor. Estas comissões acumulam as duas "matérias" em seus escopos, fundindo os interesses em benefício da sociedade. As matérias, contudo, não são fundidas e tratadas complementarmente uma em benefício da outra, mas essa fusão ocorre simplesmente de forma organizacional. Intencional ou não, a junção das matérias em uma única pauta assevera a proximidade social que caracterizam os temas, cabendo também ao contexto jurídico que as permeia um diálogo mais amplo e sólido.

Os chamados direitos humanos fundamentais buscam a proteção do indivíduo contra o arbítrio do poder estatal, e também visam estabelecer condições de vida e pleno desenvolvimento da personalidade humana. Dentro destas características, e em razão das diferentes necessidades sociais das nações, o salutar e adequado para alguns nem sempre o é para outros. A ideia de valoração da vida, sua dignidade e desenvolvimento como manutenção dos direitos humanos em países da Europa é distinta de países da África, por exemplo. Em razão disso, parte da doutrina apresenta uma classificação dos direitos humanos, dividindo-os em primeira, segunda e terceira dimensões. Outra parte entende que os direitos humanos são unos e indivisíveis, porquanto se inadmite sua divisão. 
Em que pese esta divergência doutrinária, e sem prejuízo ao presente estudo, os direitos humanos de primeira dimensão, substanciados e difundidos essencialmente na Declaração Francesa dos Direitos do Homem e do Cidadão e na Constituição dos Estados Unidos da América de $1787,{ }^{7}$ sustentam as garantias individuais e liberdades políticas, as quais se asseguram também na Constituição Federal de 1988. São direitos primordiais e indissociáveis ao mínimo exigível para o desenvolvimento humano e social, impondo limitações ao poder do Estado e sua atuação. Inexistindo tais prerrogativas, os anseios sobre a consagração dos demais elementos que permitam uma vida plena e digna restam prejudicados. Isso posto, a conquista de outros direitos complementares àquele que sequer possui garantias de liberdade e propriedade, ou mesmo de conservação da própria vida, são inertes e pouco convincentes ao meio social que permeiam.

Os direitos denominados de segunda dimensão ultrapassam as liberdades e condições mínimas existenciais, adentrando em garantias individuais e coletivas com relação a direitos econômicos, sociais, culturais, à saúde, educação, trabalhistas, entre outros. Necessitam da tutela estatal como sujeito passivo e principal agente de atuação na proteção destes direitos. Em razão do contexto histórico em que se inseriram, pode-se associar os direitos humanos de primeira dimensão ao ideal francês de liberdade perante o Estado, enquanto os direitos de segunda dimensão manifestam o marco da igualdade ante os governos intervencionistas que outrora predominaram.

\footnotetext{
${ }^{7}$ Os direitos humanos da Declaração de Virgínia e da Declaração Francesa de 1789 são, nesse sentido, direitos humanos de primeira dimensão, que se baseiam numa clara demarcação entre Estado e não Estado, fundamentada no contratualismo de inspiração individualista. São vistos como direitos inerentes ao indivíduo e tidos como direitos naturais, uma vez que precedem o contrato social. Por isso, são direitos individuais: (I) quanto ao modo de exercício - é individualmente que se afirma, por exemplo, a liberdade de opinião; (II) quanto ao sujeito passivo do direito - pois o titular do direito individual pode afirmá-lo em relação a todos os demais indivíduos, já que esses direitos têm como limite o reconhecimento do direito de outro [...] (Lafer, Celso. A reconstrução dos direitos humanos: um diálogo com o pensamento de Hannah Arendt. São Paulo: Companhia das Letras, 1988. p. 126).
} 
Esta segunda dimensão de direitos é amplamente almejada no continente americano e sua consolidação é frágil, na mesma medida que muitas nações e estados também o são. No Brasil, em razão de sua recente trajetória no desenvolvimento dos direitos humanos, apresenta-se como desafio maior. A escassez de recursos públicos e sua má administração, a diversidade e intolerância cultural e racial, entre outros tantos fatores, acabam por ferir direitos humanos de segunda dimensão. Em razão da necessidade de tutela estatal na efetivação destes direitos, neste caso fundamentalmente pelo poder Executivo, seu descumprimento passa pela necessidade de atuação do poder Judiciário.

Já a terceira dimensão de direitos humanos é, segundo Alexandre de Moraes (1997, p. 47), aquela que

[...] protege os chamados direitos de solidariedade ou fraternidade, que englobam o direito a um meio ambiente equilibrado, a uma saudável qualidade de vida, ao progresso, à paz, à autodeterminação dos povos e a outros direitos difusos.

Seguindo a trilha histórica, esta dimensão de direitos tornou-se identificável no seio social principalmente a partir da década de 60 (Canotilho, 2003), em decorrência dos fenômenos sociais e políticos transformados a partir da Segunda Guerra, pelo avanço e desenvolvimento tecnológico, e em consonância com a nova formatação de mercado e economia e organização social. Tanto quanto nos direitos de primeira e segunda dimensão, os ideais da Revolução Francesa mostram-se presentes também nesta seara, representado pelo pilar da fraternidade. Há que se solidificar a defesa dos direitos mais basilares para se almejar e sustentar os direitos mais apurados. Cada qual possui peso e relevância social em sua época perante a coletividade que os almeja.

Com relação à sustentação dos direitos humanos de segunda e terceira dimensões o papel dos poderes Executivo e Legislativo pode ser a razão do seu sucesso ou fracasso. A instituição de políticas públicas, a 
elaboração legislativa, o direcionamento dos recursos públicos, geram resultados ao encontro, ou de encontro, aos interesses humanos e sociais defendidos. $\mathrm{O}$ poder Judiciário torna-se pedra de toque, exercendo trabalho fundamental na tarefa de assegurar aos indivíduos e à sociedade a aplicação e controle das garantias fundamentais inseridas na Constituição, bem como das normas produzidas em seu reflexo, visando ao cumprimento de tais preceitos. Sua atuação permitindo o diálogo das fontes em prol da efetivação dos direitos humanos é condição fundamental. O papel de sujeito passivo do Estado pode ser dividido também com entes privados, em especial os fornecedores com relação aos seus deveres e responsabilidades tuteladas no Código de Defesa do Consumidor nas relações de consumo.

O poderio das grandes corporações, que ultrapassaram as fronteiras transnacionais e a globalização dos mercados, acarreta novos conflitos sociais, e tal realidade não pode ser tratada unicamente como fenômeno da economia.

Assim, Antônio Carlos Efing (2011, p. 48) nos correlaciona o tema:

O Direito do Consumidor como um ramo distinto dos demais ramos do direito, e tendo como fenômeno norteador a relação jurídica de consumo, abrange institutos jurídicos a cuidarem da matéria e que, como tais, tutelam-na com o objetivo de outorgar aos consumidores a proteção que lhes é devida. Sob esta ótica, compete neste momento compor um conteúdo ao Direito do Consumidor, acolhendo nesta perspectiva: normas a criarem direitos específicos e proteção devida ao consumidor; bem como normas asseguradoras da eficácia dos mesmos direitos, assim como aquelas que promovam a devida representação dos consumidores frente aos órgãos estatais detentores do poder de decisão sobre o mercado, fazendo também parte do núcleo do Direito do Consumidor os mecanismos jurídicos que visam a racionalizar e dirigir o comportamento do consumidor. 
A interdisciplinaridade das diversas áreas do Direito deve ser aplicada, valendo-se o cidadão do Código de Defesa do Consumidor como instrumento capaz também de assegurar a não violação de direitos humanos de segunda e terceira dimensões.

\section{4-OS DIREITOS DO CONSUMIDOR E A EFETIVAÇÃO DOS DIREITOS HUMANOS}

Restringir a aplicação dos direitos do consumidor a casos de substituição de produtos defeituosos ou reparação de serviços malprestados acaba por limitar demasiadamente sua extensão e visão social, a qual foi amplamente ansiada pelos criadores de seu projeto. A visão social do Código pode ser observada na amplitude do conceito de fornecedor, incluindo entes públicos, o que se estende aos concessionários de serviços, bem como a todo aquele que participa da cadeia produtiva e do mercado. Todos participam livremente em suas atividades mercantis visando ao lucro, de igual modo lhes é atribuída responsabilidade solidária perante os consumidores.

Algumas categorias de fornecedores desempenham tarefa de grande valia no desenvolvimento humano e social. Por meio de pesquisas e estudos científicos desenvolvem produtos e serviços em benefício dos consumidores, seja na área da saúde, alimentação, educação, entre outras tantas. Por sua vez, consumidores podem se tornar dependentes destes mesmos fornecedores, aos quais cumpre um dever de boa-fé e cautela, cientes de seu papel não só como entes de Direito privado que buscam lucro e resultados, mas também como entes passivos de deveres substanciados dos preceitos sociais e humanistas dispostos na legislação consumerista e sua base constitucional. 
As premissas que sustentam a defesa dos direitos humanos de segunda e terceira dimensões, tais como acesso à saúde e educação, meio ambiente equilibrado, qualidade de vida e desenvolvimento moral, dependem muitas vezes do cumprimento pelos fornecedores de preceitos dispostos no CDC.

A atuação do poder Judiciário com objetivo de obrigar o Estado a fornecer medicamentos à população, sob pena de se ferir direitos humanos, também pode ser empregada perante entes privados. Milhares de ações judiciais, em que figuram consumidores de um lado e planos de saúde de outro, por exemplo, tramitam nos tribunais pátrios. Em certos casos, o descumprimento contratual pelo fornecedor é latente, e a alegação de liberdade contratual e autonomia das partes não pode ser sustentada em desfavor do consumidor, assim como não se sustenta pelo Estado a alegação da aplicação do princípio da reserva do $\operatorname{possíve}^{8}$ na negativa de fornecimento de medicamentos aos cidadãos.

O descumprimento contratual pelo fornecedor de serviços de saúde não fere somente direitos do cidadão como consumidor, mas também direitos humanos fundamentais. Em muitos casos esta negativa de atendimento pode acarretar danos físicos e morais irreparáveis, ou até mesmo risco de morte.

\footnotetext{
${ }^{8}$ A teoria da reserva do possível, portanto, tal qual sua origem, não se refere direta e unicamente à existência de recursos materiais suficientes para a concretização do direito social, mas à razoabilidade da pretensão deduzida, com vistas a sua efetivação (...) Nesta perspectiva, a teoria da reserva do possível passou a ocupar o lugar que antes era ocupado pela teoria das normas programáticas, pela separação dos poderes e pela discricionariedade administrativa, no sentido de que, se antes se entendia pela impossibilidade jurídica de intervenção do poder Judiciário na efetivação dos direitos fundamentais, agora se entende pela ausência da previsão orçamentária (Mânica, Fernando Borges. Teoria da Reserva do Possível: Direitos Fundamentais a Prestações e a Intervenção do Poder Judiciário na Implementação de Políticas Públicas. Revista Brasileira de Direito Público, Belo Horizonte, ano $5, \mathrm{n}^{\mathrm{o}}$ 18, p. 169-186, jul./set. 2007).
} 
Concessionárias de serviços públicos de água e saneamento enquadram-se no conceito de fornecedor descrito pelo CDC. A qualidade e o alcance de seus serviços são preponderantes para que se sustentem as condições mais básicas de higiene e saúde. Ao se permitir que concessionárias de serviços públicos, de um lado, distribuam indistintamente lucros aos seus acionistas, e de outro mantenham serviços precários aos consumidores, cria-se um cenário que figura em contrassenso aos preceitos constitucionais sociais.

Nestes casos, o cidadão-consumidor pode valer-se não somente das regras do CDC para efetivação de seus direitos, mas também dos princípios de direitos humanos, unindo forças em busca de algo tão simples e basilar, mas nem sempre inatingível, como a manutenção da vida, saúde e dignidade. E ainda que soe contraditório, o mesmo poder Executivo que por vezes é forçado pelo poder Judiciário a atender a anseios e necessidades sociais mínimas aos cidadãos, em outras tantas é atuante nas causas de defesa dos direitos dos consumidores.

O CDC dispõe de capítulo dedicado à formação da Política Nacional das Relações de Consumo, notadamente inserida no artigo $4^{0}$ do Código, visando ao atendimento ao consumidor e pondo a termo de modo pormenorizado as garantias e as ações a serem empregadas com fim maior de prezar pela segurança, educação, informação e demais princípios garantidores da dignidade do cidadão-consumidor mediante a atuação estatal. Esta intervenção do Estado, segundo Rizzatto Nunes, ${ }^{9}$ é questão básica

\footnotetext{
${ }^{9}$ Em complemento, assevera que nos casos de medicamentos únicos para doenças graves, nos serviços públicos, no suprimento de alimentos básicos, etc., justifica-se a intervenção direta para garantir o suprimento ao consumidor. Até no aumento exagerado de preços isso pode ocorrer, desde que se trate de caso de necessidade. Esse princípio da garantia do suprimento das necessidades do consumidor está em consonância com o princípio maior básico que lhe dá sentido, que é o da liberdade de agir e escolher, garantido no texto constitucional (art. $1^{\circ}$, III, art. $3^{\circ}$, I, art. $5^{\circ}$ caput, entre outros). (Nunes, Luiz Antonio Rizzatto. Comentários ao código de defesa do consumidor. São Paulo: Saraiva, 2000).
} 
em consonância ao disposto no Código, podendo, inclusive, intervir no domínio econômico em relação à necessidade do consumidor a certos produtos e serviços.

Por sua vez, os artigos 105 e 106 do Código de Defesa do Consumidor introduzem o Sistema Nacional de Defesa do Consumidor, materializando-se as formas e possibilidades de se dispor do Estado para amparo à questão. O órgão federal designado para esta tarefa será responsável, conforme inciso I do artigo 106, por planejar, elaborar, propor, coordenar e executar a Política Nacional de Proteção ao Consumidor. Atualmente a função está sob a responsabilidade da Secretaria Nacional do Consumidor - Senacon, ${ }^{10}$ criada em 2012 e vinculada ao Ministério da Justiça.

Neste cenário, o Programa de Orientação e Proteção ao Consumidor (Procon) desenvolve importante papel, não só na tutela dos direitos individuais dos consumidores, mas também em questões coletivas envolvendo acessibilidade de deficientes físicos, segurança dos produtos postos no mercado, fiscalização de websites de compras pela Internet em razão dos hipervulneráveis, valendo-se dos mecanismos dispostos no CDC em prol da coletividade.

Tamanho é o caráter social e difuso do CDC que a Política Nacional das Relações de Consumo também indica a atuação do Ministério Público na defesa dos consumidores, o que mais uma vez demonstra a intenção do legislador de se valer de todos os instrumentos hábeis para concretizar os dispositivos lá inseridos. Esta indicação acompanha a própria natureza constitucional das atribuições do Parquet (Ministério Público), podendo atuar nos interesses da coletividade dos consumidores, seja em conjunto

${ }^{10}$ Senacon foi criada por meio do Decreto 7.738 , de 28 de maio de 2012 , o qual a designa para “exercer as competências estabelecidas na Lei 8.078, de 11 de setembro de 1990". 
com os Procons, ou autonomamente, valendo-se de instrumentos como a Ação Civil Pública, o Termo de Ajustamento de Conduta, o Inquérito Civil, de acordo com o caso concreto.

Ainda há as instituições privadas de proteção aos consumidores, as quais registram reclamações e os orientam acerca de seus direitos e dos deveres dos fornecedores. Essas instituições utilizam principalmente a Internet como forma de divulgar o zelo com o qual os fornecedores lidam com possíveis problemas decorrentes de seus produtos ou serviços.

Seja pelos Procons, Ministério Público, associações de consumidores, instituições privadas, ou mesmo pela ação do poder Judiciário, fato é que o Código de Defesa do Consumidor criou elementos para permitir que estes agentes atuem em benefício dos cidadãos consumidores, demonstrando assim a força normativa do Código e seu alcance e papel social no dia a dia de todos. Seus efeitos, além de permitirem maior harmonia entre consumidores e fornecedores, possibilitam o próspero desenvolvimento social das pessoas, que por sua vez consomem para subsistir.

\section{CONCLUSÃO}

No início do século 20, ainda que o êxodo rural iniciasse sua trajetória hoje predominante, os cidadãos conduziam sua vida mediante relação mais pessoal e artesanal perante os fornecedores de produtos e serviços postos no mercado. Tais fornecedores, entretanto, representavam pequena parcela de influência na subsistência dos cidadãos, e o Direito também pouco dispunha a respeito das relações de consumo.

Atualmente, imaginar o ordenamento jurídico pátrio amparando-se tão somente nas bases do Direito Civil para tutelar os consumidores é tarefa difícil, e afetaria severamente a população ante as conquistas até então obtidas, todas visando a equilibrar a relação perante os fornecedores. 
Ainda que parte dos fornecedores aja com desídia à sociedade, prezando indiscriminadamente seu lucro, o cidadão-consumidor está ciente de que pode valer-se do Código de Defesa do Consumidor para assegurar não somente sua subsistência, mas também sua dignidade em razão da necessidade indissociável de consumir para manutenção da própria vida.

Dados e traçados tais elementos, não se pretendeu aqui defender que todas as formas de consumo tenham reflexos nos direitos humanos, até porque muitas delas são de produtos e serviços supérfluos e que prezam somente pela ostentação ou até mesmo difundem o consumismo desmedido. Pretende-se, todavia, solidificar e dar lugar de maior destaque ao Código de Defesa do Consumidor, o qual tende a ser cada vez mais operante em razão de seu amadurecimento.

Valer-se das proteções constitucionais e do CDC em benefício dos cidadãos-consumidores com relação a serviços de saúde, saneamento, segurança, bem como medicamentos e alimentos, garante a dignidade e plenitude social almejada pelos fundamentos de direitos humanos. Fundir as duas áreas do Direito e tratar complementarmente uma em benefício da outra é medida indispensável e mostra-se tendência em razão da importância dada nos últimos anos aos direitos sociais. Assim, o Código de Defesa do Consumidor passa também a ser efetivador e concretizador de direitos humanos em benefício da coletividade.

\section{6- REFERÊNCIAS}

BENJAMIN, Antônio Herman V.; MARQUES, Cláudia Lima; MIRAGEM, Bruno. Comentários ao Código de Defesa do Consumidor. 4. ed. São Paulo: Editora Revista dos Tribunais, 2013.

BRASIL. Lei $n^{\circ}$ 8.078, de 11 de setembro de 1990. Código de Defesa do Consumidor. Disponível em: <http://www.planalto.gov.br>. Acesso em: 4 jan. 2015. 
Superior Tribunal de Justiça. Recurso Especial $n^{0} 586.316$, da $2^{\text {a }}$

Turma, Relator: Ministro Herman Benjamin. 2007.

CANOTILHO, José Joaquim Gomes. Direito constitucional e teoria da constituição. 7. ed. Coimbra: Almedina, 2003.

CLÈVE, Clèmerson Merlin; PAGLIARINI, Alexandre Coutinho; SARLET, Ingo Wolfgang. Direitos humanos e democracia. 1. ed. Rio de Janeiro: Forense, 2007. EFING, Antônio Carlos. Fundamentos do direito das relações de consumo. 3. ed. Curitiba: Juruá, 2011.

GRINOVER, Ada Pellegrini et al. Código brasileiro de defesa do consumidor comentado pelos autores do anteprojeto. 8. ed. Rio de Janeiro: Forense, 2004.

THEODORO JUNIOR, Humberto. Direitos do consumidor: a busca de um ponto de equilíbrio entre as garantias do código de defesa do consumidor e os princípios gerais do direito civil e do direito processual civil. 4. ed. Rio de Janeiro: Forense, 2004.

LAFER, Celso. A reconstrução dos direitos humanos: um diálogo com o pensamento de Hannah Arendt. São Paulo: Companhia das Letras, 1988.

MÂNICA, Fernando Borges. Teoria da reserva do possivel: direitos fundamentais a prestações e a intervenção do Poder Judiciário na implementação de políticas públicas. Revista Brasileira de Direito Público, Belo Horizonte, ano 5, n⿳⺈ 18, p. 169-186, jul./set. 2007.

MARINS, James. Responsabilidade da empresa pelo fato do produto (Os acidentes do consumo no Código de Proteção e Defesa do Consumidor). São Paulo: Editora Revista dos Tribunais, 2000. Vol. 5.

MARQUES, Cláudia Lima. O “diálogo das fontes” como método da nova teoria geral do direito: um tributo a Erik Jayme. In: Diálogo das fontes: do conflito à coordenação de normas do direito brasileiro. São Paulo: Editora Revista dos Tribunais, 2012.

. Contratos no Código de Defesa do Consumidor: o novo regime das relações contratuais. 5. ed. São Paulo: RT, 1992. 
MORAES, Alexandre de. Direitos humanos fundamentais: teoria geral, comentários aos arts. $1^{\circ}$ a $5^{\circ}$ da Constituição da República Federativa do Brasil, doutrina e jurisprudência. São Paulo: Atlas, 1997.

MÜLLER, Friedrich. Teoria e interpretação dos Direitos Humanos Nacionais e Internacionais - especialmente na ótica da teoria estruturante do Direito. In: CLÈVE, C. M.; SARLET, I. W.; PAGLIARINI, A. C. (Coord.). Direitos humanos e democracia. Rio de Janeiro, Forense, 2007.

NUNES, Luiz Antonio Rizzatto. Comentários ao código de defesa do consumidor. São Paulo: Saraiva, 2000. . Curso de direito do consumidor. 7 ed. São Paulo: Saraiva, 2012.

PIOVESAN, Flávia. Direitos Humanos e justiça internacional: um estudo comparativo dos sistemas regionais europeu, interamericano e africano. 5. ed. São Paulo: Saraiva, 2014a.

Temas de direitos humanos. 7. ed. São Paulo: Saraiva, 2014b.

SILVA, Afonso da. Curso de Direito Constitucional Positivo. 26. ed.São Paulo: Malheiros, 2006.

TARTUCE, Flávio; NEVES, Daniel Amorim Assumpção. Manual de direito do consumidor: direito material e processual. São Paulo: Editora Método, 2012. Volume único.

Recebido em: 15/7/2015

Revisões requeridas em: 24/8/2015

Aceito em: 14/12/2015 